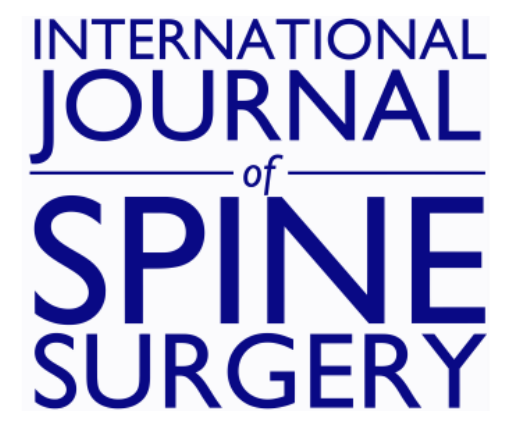

\title{
The Incidence of Lumbar Discectomy after Epidural Steroid Injections or Selective Nerve Root Blocks
}

William F. Lavelle, Thomas Mroz and Isador Lieberman

Int J Spine Surg 2015, 9 ()

doi: https://doi.org/10.14444/2012

http://ijssurgery.com/content/9/12

This information is current as of April 26, 2023.

Email Alerts Receive free email-alerts when new articles cite this article. Sign up at:

http://ijssurgery.com/alerts

The International Journal of Shing Surgerhy 2397 Waterbury Circle, Suite 1,

Aurora, IL 60504, Phone: +1-630-375-1432

(C) 2015 ISASS. All Rights Reserved. 


\section{The Incidence of Lumbar Discectomy after Epidural Steroid Injections or Selective Nerve Root Blocks}

William F. Lavelle, $M D,{ }^{1}$ Thomas Mroz, $M D^{2}$ Isador Lieberman, $M D^{3}$

${ }^{1}$ Department of Orthopedic Surgery, SUNY Upstate Medical University, East Syracuse, NY, ${ }^{2}$ Center for Spine Health, The Cleveland Clinic, Cleveland, OH, ${ }^{3}$ Scoliosis \& Spine Tumor Center, Texas Back Institute, Texas Health Presbyterian Hospital, Plano, TX

\section{Abstract}

\section{Background}

The purpose of this study was to determine the use of Central Epidural Steroid Injections (ESI) and Selective Nerve Root Blocks (SNRB) along with the crossover rate to lumbar discectomy in patients with a lumbar disc herniation using retrospective records database search. Butterman et al found a crossover rate for patients with symptomatic disc herniations treated with ESI of 54\% (27/50), while Riew similarly found a 53\% (29/55) crossover patients receiving $\mathrm{SNRB}$.

\section{Methods}

The database was searched in a sequential Boolean style for patients with the diagnosis of a lumbar disc herniation (Displaced Lumbar Disc - 722.1) and a SNRB (64483) or ESI (62311) who subsequently underwent a Lumbar Discectomy (63030) over a three year time period from January 2004 through December 2006. Statistical analysis was preformed examining the impact of injection type, age, location, gender, and year.

\section{Results}

Of 482,893 patients with the diagnosis of a disc herniation, 27,799(5.76\%) underwent a lumbar discectomy. The 29,941 patients who received at least one SNRB for a disc herniation, $10.80 \%$ later underwent a lumbar discectomy. The 41,420 patients who received at least one ESI for a disc herniation 9.34\% later underwent a lumbar discectomy. There was a noted increase in injection procedures, particularly SNRB during the study with a greater than $50 \%$ increase.

\section{Conclusions}

Our examination found a much smaller, but similar crossover rate to surgery between both injection methods, which argues against one method being more effective than another in avoiding surgery. It is likely that patients are receiving these procedures more frequently during the course of conservative treatment for a disc herniation.

Level of Evidence

This was a Level III study.

KEYWords: CENTRAL EPIDURAL STERoId INJECTIONS (ESI), LUMBAR DiSCECTOMY, LUMBAR DiSC HERNIATION, SELECTIVE NERVE Root BLOCKS (SNRB)

VOLUME 9 ARTICLE 12 DOI: 10.14444/2012

\section{Introduction}

Central Epidural Steroid Injections (ESI) and Selective Nerve Root Blocks (SNRB) are often used for the non-surgical treatment of lumbar disc herniations. Numerous authors have reported on their value in treating patients with radicular pain with the possibility of delaying or even obviating the need for lumbar discectomy in well-selected patients. ${ }^{1-19}$ There are two well-performed clinical studies in the peer reviewed literature that examined the crossover rates to surgery for patients who received either ESI or SNRB. In a prospective study, Buttermann et al. found a crossover rate to surgery for patients with symptomatic disc herniations treated with ESI of 54\% $(27 / 50) .^{2}$ In a separate prospective study, Riew et al. followed patients after SNRBs during their intial follow-up of 13-28 months. In a later study that followed the same population, 76\% (16/21) of those patients who had avoided surgery at one year still 
avoided surgery at a minimum of five year followup. ${ }^{20,21}$ While well designed and executed, both studies examined relatively small patient populations in a controlled environment. In contrast, the use of injections for spinal pathology is not currently as well controlled in the general community and is postulated to have increased in recent years. However, the prevalence and distribution of this increase is unknown. Additionally, the crossover to surgery after these interventions has not been determined.

With the increasing popularity of injection procedures, it is possible that ESI and SNRB procedures are being prescribed too often. In addition, a significant number of patients who are receiving these procedures may still require surgery. Given this uncertainty, this study was designed to determine the incidence of lumbar discectomy for disc herniation after initial treatment with either ESI or SNRB.

\section{Materials and Methods}

The patient sample was extracted from a large private insurance database. The Pearl Diver Database (Pearl Diver Technologies, Inc., Fort Wayne, IN) was compiled from patient data on 18.6 million patients in 2004, 19.5 million patients in 2005, and 20.6 million patients in 2006 .

A records search within a large private insurance database was undertaken. The database was searched in a sequential fashion (Boolean style search) for patients with the diagnosis of Lumbar Disc Herniation (Displaced Lumbar Disc- 722.1) and a SNRB (64483) or an ESI (62311) who had subsequently undergone a Lumbar Discectomy (63030) over a three year time period (January 2004-December 2006). The data were retrieved from the Pearl Diver insurance database and stored in a separate, secure, and anonymous database (Microsoft Access 2003 File, Seattle, WA). This data included diagnostic codes, as well as, each procedural code performed on the patient. Though patients were de-identified in the database, each patient maintained a unique identifier for subsequent diagnostic or procedural entries. Patient demographic data for geographic location, gender and age were also recorded. Age was recorded in five year intervals, while geographic locations were divid- ed into four regions: Midwest, Northeast, South and West.

\section{Statistical Methods}

Statistical analysis was performed using NCSS 2004 (Kaysville, UT) and SPSS v15 (Chicago, IL) statistical software. Each database member was considered unique with duplicate member entries that contained unique patient procedural data paired via a relationship in the Microsoft Access file. Year of diagnosis, gender, age and location were analyzed for the entire disc herniation population, as well as, each of the interventional categories such as SNRB, ESI, and discectomy. The date of the injection (either SNRB or ESI) was compared to the date of an initial diagnosis (the date the member first appeared in the database). The patients, whose injection procedure or discectomy was their first entry into the database, were eliminated from the time analysis because we believed this did not accurately reflect the time from initial diagnosis to an injection. The percentage of patients within each of the injection subgroups that proceeded to a discectomy was reported and compared for each year of the study period. Categorical variables were analyzed using a chi squared analysis while continuous variables were analyzed utilizing an ANOVA. The value of $p<0.05$ was regarded as significant.

\section{Results}

Based on the data supplied by Pearl Diver with 58.7 million patients reviewed from their database, 482,893 unique patients carried the diagnosis of a disc herniation over the study time period. Within this unique population, 27,799 patients $(5.76 \%)$ underwent a lumbar discectomy during the entire study period. Of the 29,941 patients who received at least one SNRB for a disc herniation, 3,235 (10.80\%) later underwent a lumbar discectomy. Additionally, of the 41,420 patients who received at least one ESI for disc herniation, 3,869 patients (9.34\%) later underwent a lumbar discectomy. A breakdown of procedures by geographic location, year, and gender is shown on Table 1 and Table 2.

For 14,004 ESI patients and 7,305 SNRB patients, their injection procedure was their first entry into the patient database. The average time from the initial 
diagnosis of a disc herniation until an injection was examined for patients who received an injection within a calendar year from their diagnosis and who did not have their injection as their initial data entry in the patient database. Patients who received an ESI injection received it an average of $56.8 \pm 74.1$ days after their initial diagnosis of a disc herniation. Additionally, patients who received a SNRB received it an average of $61.7 \pm 77.8$ days after their initial diagnosis of a disc herniation. Figure 1 and Figure 2 graphically illustrate the percentage of patients who received their ESI and SNRB with respect to time from diagnosis of a disc herniation. More than half of patients

Table 1. Procedures for Patients with Disc Herniations

\begin{tabular}{|c|c|c|c|c|}
\hline & 2004 & 2005 & 2006 & Total \\
\hline \multicolumn{5}{|l|}{ Men } \\
\hline Disc Herniations & 78018 & 75405 & 82359 & 235782 \\
\hline Discectomies & 5068 & 5054 & 5788 & 15910 \\
\hline Epidural Steroid Injections & 6595 & 6075 & 7707 & 20377 \\
\hline Discectomies after ESI & 795 & 665 & 706 & 2166 \\
\hline Selective Nerve Root Blocks & 4136 & 4424 & 6499 & 15059 \\
\hline Discectomies after SNRB & 552 & 554 & 685 & 1791 \\
\hline \multicolumn{5}{|l|}{ Women } \\
\hline Disc Herniations & 81108 & 78559 & 87444 & 247111 \\
\hline Discectomies & 3805 & 3740 & 4344 & 11889 \\
\hline Epidural Steroid Injections & 6862 & 9033 & 7924 & 21043 \\
\hline Discectomies after ESI & 642 & 542 & 519 & 1703 \\
\hline Selective Nerve Root Blocks & 4086 & 4296 & 6500 & 14882 \\
\hline Discectomies after SNRB & 450 & 473 & 521 & 1444 \\
\hline \multicolumn{5}{|l|}{ Total } \\
\hline Disc Herniations & 159126 & 153964 & 169803 & 482893 \\
\hline Discectomies & 8873 & 8794 & 10132 & 27799 \\
\hline Epidural Steroid Injections & 13457 & 15108 & 15631 & 41420 \\
\hline Discectomies after ESI & 1437 & 1207 & 1225 & 3869 \\
\hline Selective Nerve Root Blocks & 8222 & 8720 & 12999 & 29941 \\
\hline Discectomies after SNRB & 1002 & 1027 & 1206 & 3235 \\
\hline
\end{tabular}

from both groups received their injection within sixty days of their initial diagnosis. Patients received an average of 2.36 ESI injections during the study period, while patients who received a SNRB received an average of 2.44 injections.

Table 3 demonstrates the rates of discectomy for both ESI and SNRB patients by year, gender, age and region of the country. There was a statistically significant drop in the rate of progression to surgery by year for ESI $(p=0.003)$, but not for SNRB ( $p=$ $0.064)$. Men had a statistically significantly higher discectomy rate after both SNRB $(p=0.001)$ and $\mathrm{ESI}(\mathrm{p}=0.001)$. The percentage of patients receiving a discectomy after both SNRB $(p=0.001)$ and ESI

\begin{tabular}{|c|c|c|}
\hline Demographics & SNRB & ESI \\
\hline Year & $(p=0.001)$ & $(p=0.001)$ \\
\hline 2004 & $5.7 \%$ & $8.5 \%$ \\
\hline 2005 & $5.4 \%$ & $8.0 \%$ \\
\hline 2006 & $7.3 \%$ & $9.2 \%$ \\
\hline Gender & $(p=0.001)$ & $(p=0.165)$ \\
\hline Male & $6.4 \%$ & $8.6 \%$ \\
\hline Female & $6.0 \%$ & $8.5 \%$ \\
\hline Age & $(p=0.001)$ & $(p=0.001)$ \\
\hline$<30$ & $4.7 \%$ & $7.1 \%$ \\
\hline $30-40$ & $6.0 \%$ & $8.3 \%$ \\
\hline $40-50$ & $6.3 \%$ & $8.7 \%$ \\
\hline $50-60$ & $6.6 \%$ & $8.9 \%$ \\
\hline$>60$ & $6.6 \%$ & $9.2 \%$ \\
\hline Region & $(p=0.001)$ & $(p=0.0001)$ \\
\hline Midwest & $6.4 \%$ & $10.6 \%$ \\
\hline Northeast & $4.4 \%$ & $5.6 \%$ \\
\hline South & $6.1 \%$ & $8.6 \%$ \\
\hline West & $8.0 \%$ & $7.9 \%$ \\
\hline
\end{tabular}

Downloaded from http://ijssurgery.com/ by guest on April 26, 2023 
$(\mathrm{p}=0.001)$ decreased with increasing patient age. There was no difference in the percentage of patients receiving surgery after both $\operatorname{SNRB}(\mathrm{p}=0.155)$ and ESI $(p=0.426)$ based on the region of the country where the patient was treated. As depicted in Figure 3 , there was a noted increase in injection procedures. EPI injections increased from $8.46 \%(13,457 / 159,126)$ to $9.21 \%(15,631 / 169,803)$; and SNRB injections increased from $5.17 \%(8,222 / 159,126)$ to $7.66 \%$ $(12,999 / 169,803)$. Also, the overall rate of discectomies during the study period increased slightly from $5.58 \%$ to $5.97 \%$. A comparison of the overall discectomy rates between ESI and SNRB yielded no

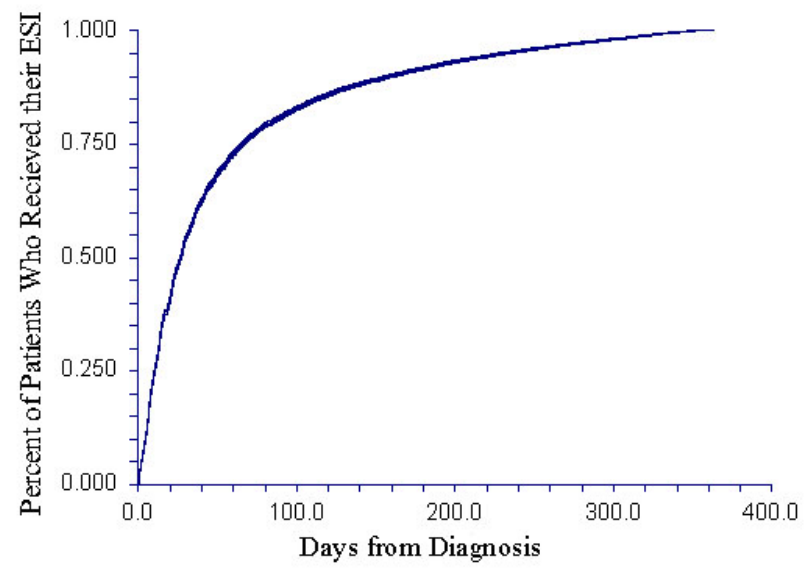

Fig. 1. Percentage of Patients who received their ESI with respect to Time from Diagnosis- The percentage of patients who received their ESI is illustrated with respect to time. Most patients received their injection prior to sixty days after diagnosis.

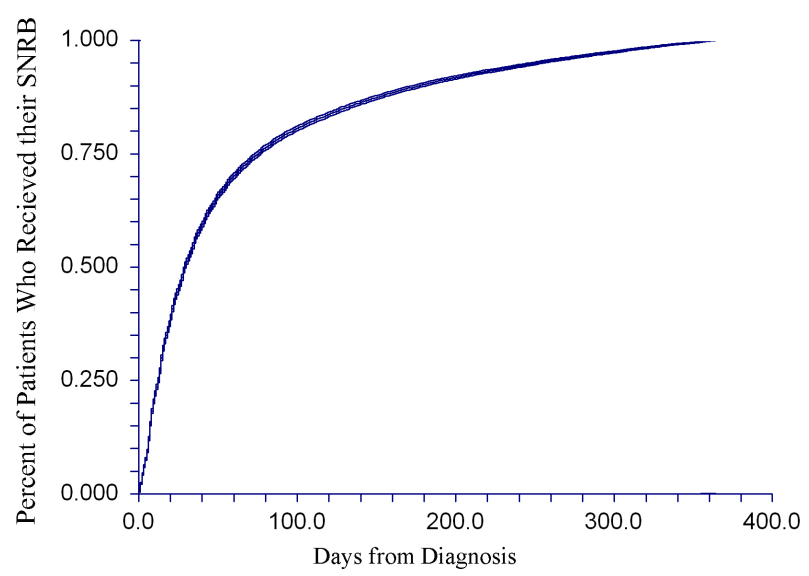

Fig. 2. Percentage of Patients who received their SNRB with respect to Time from Diagnosis- The percentage of patients who received their SNRB is illustrated with respect to time. Most patients received their injection prior to sixty days after diagnosis. statistical difference $(\mathrm{p}=0.1580)$, with an overall percentage of patients receiving a discectomy of 9.34\% $(3,869 / 41,420)$ for ESI and $10.80 \%(3,235 /$ $29,941)$ for SNRB.

\section{Discussion}

There is a debate in the literature about which type of spinal injection ESI versus SNRB is more effective for relieving pain and possibly preventing surgery. Both the Buttermann and Riew studies found a 50\% crossover rate in their studies to the surgical treatment arm. ${ }^{2,20,21}$ Our examination of a much larger, but

\begin{tabular}{|c|c|c|c|}
\hline & $\begin{array}{r}\text { SNRB Patients } \\
\text { Receiving a } \\
\text { Discectomy }\end{array}$ & $\begin{array}{c}\text { ESI Patients } \\
\text { Receiving a } \\
\text { Discectomy }\end{array}$ & $\begin{array}{l}\text { All Patients } \\
\text { Receiving a } \\
\text { Discectomy }\end{array}$ \\
\hline Year & $(p=0.064)$ & $(p=0.003)$ & $(p=0.003)$ \\
\hline 2004 & $10.7 \%$ & $10.7 \%$ & $5.9 \%$ \\
\hline 2005 & $11.5 \%$ & $9.8 \%$ & $5.5 \%$ \\
\hline 2006 & $10.4 \%$ & $7.8 \%$ & $5.8 \%$ \\
\hline Gender & $(p=0.001)$ & $(p=0.001)$ & $(p=0.001)$ \\
\hline Male & $11.9 \%$ & $10.6 \%$ & $6.7 \%$ \\
\hline Female & $9.7 \%$ & $8.1 \%$ & $4.8 \%$ \\
\hline Age & $(p=0.001)$ & $(p=0.001)$ & $(p=0.008)$ \\
\hline$<30$ & $15.6 \%$ & $12.7 \%$ & $5.9 \%$ \\
\hline $30-40$ & $14.1 \%$ & $12.3 \%$ & $7.0 \%$ \\
\hline $40-50$ & $11.3 \%$ & $9.8 \%$ & $6.1 \%$ \\
\hline $50-60$ & $8.0 \%$ & $7.6 \%$ & $5.0 \%$ \\
\hline$>60$ & $7.5 \%$ & $5.1 \%$ & $4.4 \%$ \\
\hline Region & $(p=0.155)$ & $(p=0.426)$ & $(p=0.02)$ \\
\hline Midwest & $11.0 \%$ & $9.4 \%$ & $6.3 \%$ \\
\hline Northeast & $9.0 \%$ & $8.6 \%$ & $3.5 \%$ \\
\hline South & $11.0 \%$ & $9.5 \%$ & $6.3 \%$ \\
\hline West & $10.8 \%$ & $9.3 \%$ & $5.5 \%$ \\
\hline
\end{tabular}


far less controlled population, found a much smaller overall progression rate to surgery, but similar rates between both injection methods utilized. This finding contradicts the possibility that one method of injection for lumbar disc herniations is more effective than another in the avoidance of surgery.

The reader should be cautioned that this study is limited by its design. An obvious flaw of this database review is that without radiographic confirmation of the disc herniation and stringent review criteria for the reporter's surgical indications, it is difficult to conclude the real number of herniated discs that would have been treated surgically as opposed to being simply offered an injection of any type. Keeping this in mind, the data in the current study demonstrates the rate of lumbar discectomy after either a SNRB or an ESI in this study is smaller than report- ed in prior randomized control trials. This may suggest that either ESIs or SNRBs are more beneficial than previously suspected. Another reason may be that physicians are administering more injections during the course of non-operative management for a disc herniation. In both the Buttermann and Riew studies, ${ }^{2,20,21}$ the patients that were included demonstrated discrete radiographic evidence of an acute and compressive disc herniation. Conservative measures, excluding injection, were attempted for at least six weeks before inclusion in these studies. ${ }^{2,20,21}$ Our study found an average time from diagnosis to injection of approximately eight weeks, 56.8 days, for patients receiving an ESI and 61.7 days for patiently receiving an SNRB. However, a large portion of both groups had the patient's injection listed as their initial entry into the database. If our analysis had included those patients whose initial entry into the
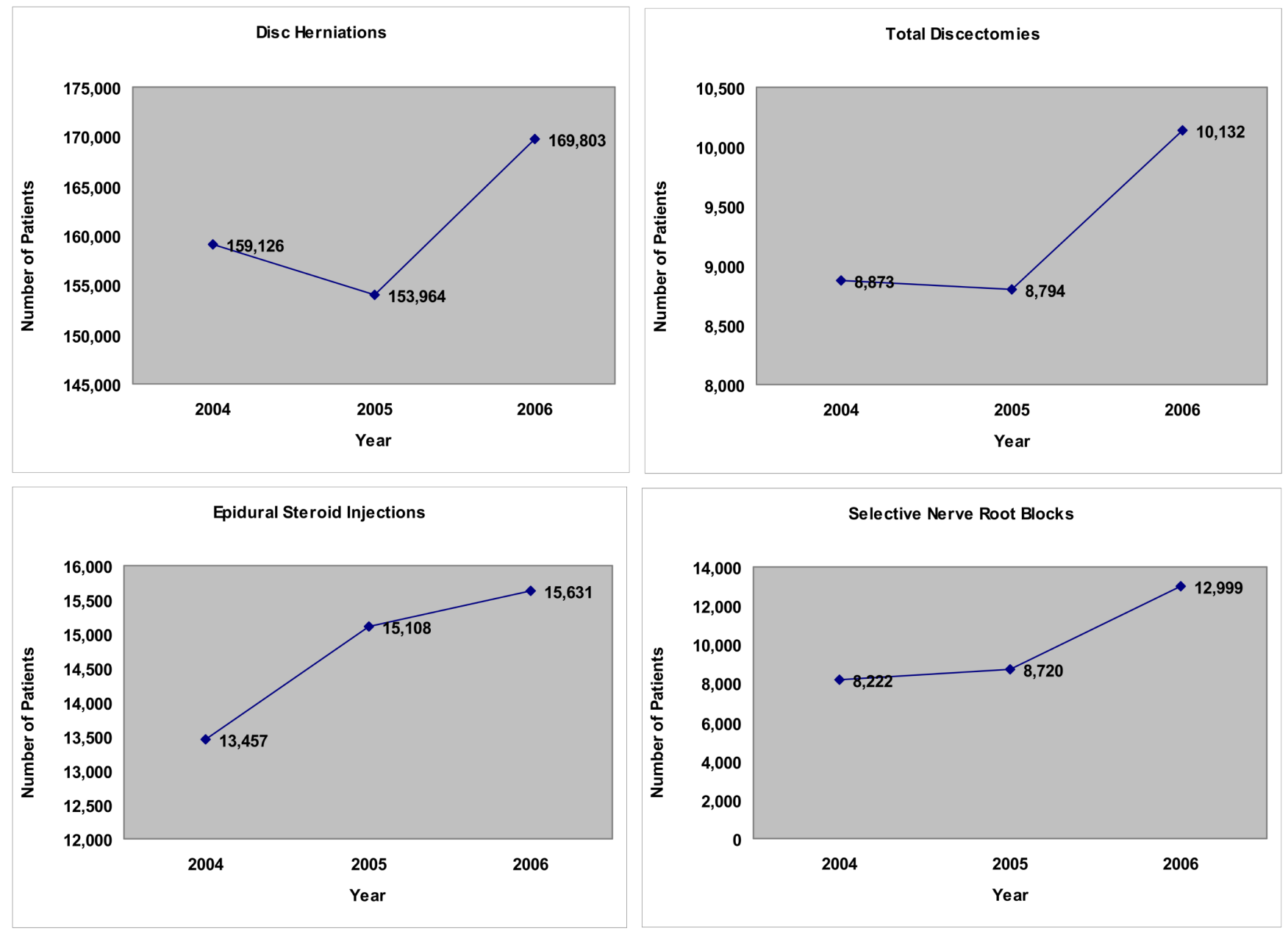

Fig. 3. Absolute Increase in Diagnosis of Disc Herniations and Associated Procedures- The absolute increase in disc herniations and procedures is shown. There was a much greater rise in number of SNRB injections. 
database was their injection procedure, the average time from diagnosis to injection would have been significantly lowered to 36.9 days for patients receiving ESI and 45.7 days for those receiving SNRB.

This review simply examined patients who had a diagnosis of a disc herniation from a physician. ESI and SNRB are both treatments intended to reduce the inflammation. Our study did not consider the type of injection chosen and may have depended on the perceived need, the patient's HNP, or physician preference. Typically, a translaminar injection is considered when multiple nerves are affected by a disc herniation or if there is a need to treat a larger area of compression as opposed to a selective nerve root injection where a clearly identified area of pathology or the response to an injection is needed to diagnose the affected area. Based on the current study design, there is no way to determine the criteria used by the diagnosing physician, nor is there a means to determine the methods of conservative treatment used prior to their procedures. As noted in Buttermann's study, the patients who had a successful ESI were twice as likely to have an extruded or sequestered disc ( $57 \%$ compared to $26 \%, \mathrm{p}=0.036)$, and were more likely to have a hydrated herniated disc (a high signal on T2-weighted magnetic resonance image, $p$ $=0.0075)$. As pointed out in a recent review of MRI images from the SPORT trial ${ }^{22}$, there is excellent inter-reader reliability for disc morphology; however, only moderate reliability for thecal sac compression, as well as, nerve root impingement. These characteristics, in particular, the compressive nature of the disc herniation, were important inclusion criteria in both the Riew and Buttermann studies. These variables could not be examined in our database analysis; and are therefore, a limitation to our analysis.

Additionally, our study found a statistically significant difference in the discectomy rate for patients receiving an ESI by year. In 2004, 10.7\% of patients received a discectomy after an ESI injection, while only 7.8\% of patients received a discectomy after an ESI in 2006. There was also a trend toward a decrease in the crossover rate for SNRB that did not reach statistical significance. This finding may perhaps indicate improved effectiveness for the injection procedures. It may also indicate a trend toward more injections in a population that otherwise would not have been in danger of proceeding to surgery and would have recovered with continued conservative measures that did not include injections.

There was a small gender difference in crossover rate for both ESI and SNRB that was found to be statistically significant. However, looking at gender differences in discectomy rates for the entire study population, only $4.8 \%$ of women proceeded to a discectomy, while $6.7 \%$ of men proceeded to discectomy.

Age was a significant factor influencing crossover rates for both ESI and SNRB. It appeared that patients were less likely to proceed to surgery after either type of injection if they were older, particularly if they were more than 50-60 years of age. This trend of a decreased conversion to discectomy was seen in the entire study population with the diagnosis of a disc herniation, but not to the extent that is was seen in the injection populations. This may indicate that patients who were older were more inclined to consider an injection, but less inclined to consider surgery. It also suggests a potential for injections to be more efficacious in treating radiculopathy in older patients. However, this cannot be concluded with this study design.

Geographic variation was also noted within our study. Similar to the conclusions of Friedly and colleagues, with respect to ESIs, patients treated in the southern region of the country were more likely to undergo an ESI. ${ }^{23}$ There was also a statistically higher discectomy rate in the southern region of the country. In both the study by Friedly et al. and our study, there was a lower rate of ESI and discectomy in the northeast region of the country.

\section{Conclusion}

Using an administrative database to define the patients did not permit us to separate out the different disc syndromes. Disc herniations are exceedingly common on MRIs. The same patient could be diagnosed with lumbago, sciatica, stenosis, degenerative disc disease, or herniation disc. The clinician's choice of diagnostic term/code might be influenced by the treatment he/she wishes to administer. These 
are certainly limitations to a retrospective database search that is based solely on CPT and ICD9 codes.

The treatment of lumbar disc herniation remains controversial. While most physicians recommend some form of early physical therapy, there is not a standardized protocol for conservative treatment with the spine community at large. Therefore, this is another limitation of our study.

The data demonstrated a sharp increase in the percentage of patients with the diagnosis of a disc herniation who received $\mathrm{SNRB}$, in particular. This rise was significantly larger than the percentage of patients with disc herniations that proceeded to discectomy. Such a sharp increase in SNRB procedures may suggest that they are becoming over utilized. Despite an injection, $10 \%$ of patients required a discectomy. This interpretation should be viewed with a degree of caution because the current study is an isolated sample based on insurance data of patients treated between 2004 and 2006 and may not reflect more global trends.

In spine surgery, it is common practice to thoroughly exhaust all conservative measures before any operation. Despite the fact that repeated steroid injections have not been proven to reduce the need for knee replacement, and are believed by some surgeons to be deleterious to the knee joint based upon animal studies of cartilage, injections into knees for a variety of arthritic conditions is commonplace. In the same light as knee injections, despite an increase in popularity in spine injections, the role and effectiveness of spinal injections remains controversial. As we hypothesized, despite a rise in the rate of spine injections, in particular SNRBs, the overall discectomy rate has not declined, which lends to the conclusion that ESI and SNRB procedures are being over utilized.

\section{References}

1. Beliveau P: A comparison between epidural anaesthesia with and without corticosteroid in the treatment of sciatica. Rheumatol Phys Med. 1971; 11:40-3.
2. Buttermann GR: Treatment of lumbar disc herniation: epidural steroid injection compared with discectomy. A prospective, randomized study. J Bone Joint Surg Am. 2004 Apr; 86-A(4):670-9.

3. Carette $S$, Leclaire R, Marcoux S, Morin F, Blaise GA, St-Pierre A, Truchon R, Parent F, Levesque J, Bergeron V, Montminy P, Blanchette C: Epidural corticosteroid injections for sciatica due to herniated nucleus pulposus. $N$ Engl J Med. 1997; 336:1634-40.

4. Cuckler JM, Bernini PA, Wiesel SW, Booth RE Jr, Rothman RH, Pickens GT: The use of epidural steroids in the treatment of lumbar radicular pain. A prospective, randomized, double-blind study. JBone Joint Surg Am. 1985; 67:63-6.

5. Dilke TF, Burry HC, Grahame R: Extradural corticosteroid injection in management of lumbar nerve root compression. Br Med J. 1973; 2:635-7.

6. Helliwell M, Robertson JC, Ellis RM: Outpatient treatment of low back pain and sciatica by a single extradural corticosteroid injection. Br J Clin Pract. 1985; 39:228-31.

7. Johnson BA, Schellhas KP, Pollei SR: Epidurography and therapeutic epidural injections: technical considerations and experience with 5334 cases. $A m ~ J$ Neuroradiol. 1999; 20:697-705.

8. Klenerman L, Greenwood R, Davenport HT, White DC, Peskett S: Lumbar epidural injections in the treatment of sciatica. Br J Rheumatol. 1984; 23:35-8.

9. Krempen JF Smith BS: Nerve-root injection. A method for evaluating the etiology of sciatica. J Bone and Joint Surg. 1974 Oct; 56-A: 1435-1444.

10. Macnab I: Negative disc exploration: An analysis of the causes of nerve root involvement in sixtyeight patients. J Bone and Joint Surg. 1971 July; 53-A: 891-903.

11. Mathews JA, Mills SB, Jenkins VM, Grimes SM, Morkel MJ, Mathews W, Scott CM, Sittampalam Y: Back pain and sciatica: controlled trials of manipulation, traction, sclerosant and epidural injections. Br J Rheumatol. 1987; 26:416-23.

12. Ridley MG, Kingsley GH, Gibson T, Grahame $\mathrm{R}$ : Outpatient lumbar epidural corticosteroid injection in the management of sciatica. Br J Rheumatol. 1988; 27:295-9.

13. Snoek W, Weber H, Jorgensen B: Double blind 
evaluation of extradural methyl prednisolone for herniated lumbar discs. Acta Orthop Scand. 1977;

48:635-41.

14. Spaccarelli KC: Lumbar and caudal epidural corticosteroid injections. Mayo Clin Proc. 1996;

71:169-78.

15. Stanley D, McLaren MI, Euinton HA, Getty CJ: A prospective study of nerve root infiltration in the diagnosis of sciatica. A comparison with radiculography, computed tomography, and operative findings. Spine. 1990; 15:540-543.

16. Tajima T, Furukawa K, Kuramochi E: Selective lumbosacral radiculography and block. Spine. 1980; 5:68-77.

17. Van Tulder MW, Koes BW, Bouter LM: Conservative treatment of acute and chronic nonspecific low back pain. A systematic review of randomized controlled trials of the most common interventions.

Spine. 1997; 22: 2128-2156.

18. Weinstein SM, Herring SA, Derby R: Contemporary concepts in spine care. Epidural steroid injections. Spine. 1995; 20:1842-6.

19. Yates DW: A comparison of the types of epidural injection commonly used in the treatment of low back pain and sciatica. Rheumatol Rehabil. 1978; 17:181-6.

20. Riew KD, Park JB, Cho YS, Gilula L, Patel A, Lenke LG, Bridwell KH: Nerve root blocks in the treatment of lumbar radicular pain. A minimum fiveyear follow-up. J Bone Joint Surg Am. 2006 Aug; 88(8):1722-5.

21. Riew KD, Yin Y, Gilula L, Bridwell KH, Lenke
LG, Lauryssen C, Goette K: The effect of nerve-root injections on the need for operative treatment of lumbar radicular pain. A prospective, randomized, controlled, double-blind study. J Bone Joint Surg Am. 2000 Nov; 82-A(11):1589-93.

22. Lurie JD, Tosteson AN, Tosteson TD, Carragee E, Carrino J, Kaiser J, Sequeiros RT, Lecomte AR, Grove MR, Blood EA, Pearson LH, Herzog R, Weinstein JN: Reliability of magnetic resonance imaging readings for lumbar disc herniation in the Spine Patient Outcomes Research Trial (SPORT). Spine. 2008 Apr 20; 33(9):991-8.

23. Friedly J, Chan L, Deyo R: Geographic variation in epidural steroid injection use in medicare patients. J Bone Joint Surg Am. 2008 Aug; 90(8):1730-7.

\section{Disclosures}

The authors declare no relevant disclosures.

\section{Corresponding Author}

William Lavelle, MD, Department of Orthopedic Surgery, SUNY Upstate Medical University, 6620 Fly Road, Suite 200, East Syracuse, NY 13057.

lavellew@upstate.edu

Published 29 April 2015.

This manuscript is generously published free of charge by ISASS, the International Society for the Advancement of Spine Surgery. Copyright @ 2015 ISASS. To see more or order reprints or permissions, see http://ijssurgery.com. 